\title{
Intratextos-
}

\section{A CONSTRUÇÃO DE ESTIGMAS COMO INSTRUMENTO DE DOMINAÇÃO: CONTRIBUIÇÃO DE NORBERT ELIAS PARA A COMPREENSÃO DOS SUJEITOS DA EJA}

\author{
Edmar Augusto Semeão Garcia ${ }^{1}$
}

\begin{abstract}
RESUMO
O presente trabalho versa a educação de jovens e adultos e a construção de práticas estigmatizadoras aos sujeitos sem escolaridade à luz dos conceitos de interdependência e figuração de Norbert Elias. Tais conceitos permitem compreender as diferentes ocupações sociais e de colaboração dos grupos, seja ele analfabeto ou não. Contudo, diante de estigmatizações pelo diferencial que é estarem analfabetos, torna-se relevante para este trabalho as contribuições de Goffman e Becker no que diz respeito às aproximações dos conceitos de estigma e outsider para a compreensão dos fatores que levam aos adjetivos citados. Assim, conseguiremos aproximar as ideias dos autores para com as de Elias tendo-o como principal nesse trabalho através de um aparato bibliográfico desenvolvido ao longo de sua vida por este grande sociólogo. O objetivo desse trabalho é abordar como as adjetivações são reproduzidas para colocar dentro de uma balança a superioridade/inferioridade de determinado grupo através de uma construção lenta, mas eficiente dentro da sociedade. Assim sendo, tendo como norte a ideia de que o estigma é uma construção social gradativa, permite compreendermos através de Elias o processo de construção desse costume. O trabalho está organizado em três partes. A primeira corresponde a uma breve contextualização da EJA; a segunda traz apontamentos contidos nos trabalhos de Elias; na terceira parte os conceitos de Becker e Goffman e; por fim as considerações finais acerca da contribuição deste autor tardiamente reconhecido por seus brilhantes trabalhos.
\end{abstract}

PALAVRAS-CHAVE: EJA; estigma; figuração; interdependência; sociologia

\begin{abstract}
The present work focuses on the education of youth and adults and the construction of stigmatizing practices to subjects without schooling in the light of the concepts of interdependence and figuration of Norbert Elias. Such concepts allow us to understand the different social and collaborative occupations of groups, whether they are illiterate or not. However, faced with stigmatization by the differential of being illiterate, Goffman and Becker's contributions regarding approximations of the concepts of stigma and outsider to the understanding of the factors that lead to the cited adjectives become relevant to this work. Thus, we will be able to approximate the ideas of the authors to those of Elias having it as the main

\footnotetext{
${ }^{1}$ Bacharel Interdisciplinar em Ciências Humanas UFJF. Bacharel em Ciências Sociais UFJF. Licenciado em Ciências Sociais UFJF. Pós-graduado em Ensino de Sociologia no Ensino Médio UFSJ. Mestrando em Educação UNIFAL. ORCID: https://orcid.org/0000-0003-3960-0647
} 


\section{Intratextos-}

one in this work through a bibliographic apparatus developed throughout his life by this great sociologist. The objective of this work is to approach how adjectives are reproduced to place within a balance the superiority/inferiority of a given group through a slow but efficient construction within society. Thus, having as its north the idea that stigma is a gradual social construction, it allows us to understand through Elias the process of constructing this custom. The work is organized in three parts. The first corresponds to a brief contextualization of EJA; the second brings notes contained in the works of Elias; in the third part the concepts of Becker and Goffman and; finally the final considerations about the contribution of this author late recognized for his brilliant works.

KEYWORDS: EJA; stigma; figuration; interdependence; sociology

\section{Apontamentos iniciais sobre a Educação de Jovens e Adultos}

A educação de jovens e adultos faz parte do ensino em nosso país desde o século $\mathrm{XX}^{2}$. Da conhecida educação popular até a sua configuração como EJA ${ }^{3}$, ela passou por momentos onde o direito de escolarizar-se independentemente da idade não era reconhecido. Tal reconhecimento advindo através da Carta magma de $1988^{4}$, significou uma ruptura no processo de negação enquanto direito para esse público.

Destarte esse movimento, os sujeitos da EJA passaram por momentos onde o acesso à educação não significava reconhecimento enquanto indivíduos dotados das faculdades mentais. Em outros termos, ao longo do século XX algumas campanhas que visavam assistir o público que estava longe da escola, partiam da ideia infantilizadora e/ou muitas vezes insinuando que se tratavam de seres endógenos e, portanto, havia a necessidade de serem iluminados pela oferta do ensino. Afinal, eram sujeitos incapazes e precisavam de um norte em suas vidas. A ideia de que sendo analfabetos eram serem fracassados e sem condições de sobreviver, se fez por muito tempo presente através de uma construção dentro da sociedade brasileira.

\footnotetext{
${ }^{2}$ Contudo, após a segunda metade do século XIX a educação já era tema de preocupação entre alguns políticos sobretudo para fins específicos conforme vai destacar Vanilda Paiva em seu livro "História da Educação Popular no Brasil: educação popular e educação de adultos".

${ }^{3}$ A partir desse momento, referir-me-ei a educação de jovens e adultos dessa forma.

${ }^{4}$ A constituição 1934 foi a primeira a destacar que a escolarização era direito independente da idade. Todavia, a educação para jovens e adultos passou por grandes momentos onde esse direito era negado. A carta de 1988 significou apresentar o direito a educação independente da idade.
} 


\section{Intratextos-}

Um exemplo acerca dessa questão está presente nos documentos referentes ao SIRENA ${ }^{5}$ (Sistema Rádio Educativo Nacional). Importante observar nesse documento a visão marcada fortemente pela ideia de seres ignorantes. Em sua justificativa para tal viabilização do projeto, o então Diretor Geral do Departamento Nacional de Educação Heli Menegale destacou os motivos para a criação do programa. Assim, logo em sua primeira página a orientação geral que teria era:

o conjunto de finalidades do SIRENA coincide com os intêresses próprios da educação fundamental:

1) proporcionar condições favoráveis ao desenvolvimento do homem no meio em que vive;

2) torná-lo útil a si mesmo;

3) torná-lo útil a família;

4) torná-lo útil à comunidade;

5) torná-lo útil ao país;

6) dar-lhe oportunidade de liderança, na comunidade;

7) infundir-lhe idéias de compreensão e de solidariedade universal (SIRENA, 1957, p. 1)

Observe que havia uma necessidade advinda do Estado - reproduzida pela sociedade-, em transformar a vida do analfabeto, equivocadamente, a torna-se útil a si e para as diferentes figurações que desempenhavam como o próprio documento salienta. Evidentemente esquecendo-se de que o sujeito analfabeto ocupa dentro da sociedade diferentes papéis assim como as pessoas que se escolarizam. $\mathrm{O}$ fato de estarem analfabetos naquele momento não os impedia de ocuparem qualquer outro espaço de figuração.

É relevante salientar que a relação entre adultos e marginalidade já estava presente desde as primeiras ações de escolarização dos jovens e adultos à medida que estes não possuíam a educação formal entendida como os saberes escolares, sendo fortalecida a ideia de sujeitos incapazes. Consequentemente, levando a ideia de serem pessoas doentes conforme frisado acima, desconsiderando também outras formas de aprendizado bem como de outros saberes dentro das relações nos diferentes espaços da sociedade.

Assim sendo, Pinto (1983) salienta acerca da visão ingênua na educação que se tinha sobre a educação aos jovens e adultos na qual era necessário

Despertar uma atitude geral de alarme social em face da gravidade do problema do analfabetismo, o que é um meio seguro de fazê-lo

\footnotetext{
${ }^{5}$ Disponível em http://forumeja.org.br/sirena
} 


\section{Intratextes-}

incompreendido em suas verdadeiras causas objetivas. Em lugar de reconhecer no analfabetismo um índice natural da etapa em que se encontra o processo de desenvolvimento nacional, apresenta-o como uma anormalidade, uma monstruosidade que é preciso "combater", "erradicar". Estas expressões, freqüentes na oratória dos promotores de campanhas de alfabetização, demonstram bem os pedagogos desta estirpe concebem o analfabetismo como um "mal", uma "enfermidade", uma "endemia", uma "erva daninha". Assim, enquanto este for o pensamento dominante não há possibilidade de que o educador ou o legislador entre pela via de resolução do problema do analfabetismo, que é de fato uma deficiência culturalmente grave, mas que nada tem de sociologicamente anormal”. (PINTO, 1983, p. 63)

Percebe-se inicialmente neste trecho duas situações: a primeira reforça aquilo dito anteriormente. Ou seja, o caráter marginal e patológico que se tinha ao analisar o sujeito analfabeto. A segunda questão corresponde a refutação que o próprio autor aborda ao desconstruir a ideia de patologia, sendo enfático ao destacar que a deficiência se encontra no Estado. O alto índice de analfabetos era um problema decorrente de outras situações onde o Estado não conseguia (ou não queria) reparar.

No que diz respeito ao ato de estigmatizar esses analfabetos, Darcy Ribeiro em um Congresso de Alfabetização em 1990 organizado pelo GETA - Grupo de Estudos e Trabalhos em Alfabetização afirma: "Deixem os velhinhos morrerem em paz! Deixem os velhinhos morrerem em paz!" (HADDAD, 1997). Essa fala é muito significativa, pois, traz uma ideia muito presente ainda naquela época - pós constituinte - sobre a visão dos sujeitos da EJA. Contudo, na figura de Darcy Ribeiro, o mesmo acreditava que estes jovens e adultos já estavam adaptados à condição de analfabetos e não se deveria investir nesta modalidade de ensino, contrariando o direito reconhecido através da Carta magna de 1988.

Paralelo a assertiva de Darcy Ribeiro que tratou os analfabetos como sujeitos endógenos devido a sua baixa escolarização, Elias (2001) salienta em seu livro a dificuldade que a sociedade possui em lidar com os velhos. Assim, o autor frisa

A crueldade que se expressa na zombaria dos velhos desvalidos, e também da feiúra de alguns velhos e velhas, era provavelmente maior antigamente do que hoje. Mas decerto não desapareceu. Está intimamente relacionada a uma mudança muito característica nas relações interpessoais, que tem lugar quando as pessoas envelhecem ou estão no leito de morte; quando envelhecem ficam potencial ou realmente menos fortes em relação aos mais jovens. (ELIAS, 2001, p. 82) 


\section{Intratextos-}

Há um componente na explanação de Darcy e no que salienta Elias que os coloca em consonância: o caráter improfícuo que o velho possui. No caso da EJA, estamos pensando em seres que por estarem analfabetos constituem-se como algo desinteressante a população e ao Estado.

A rigor, não se vê utilidade alguma tanto aos idosos quanto as pessoas analfabetas. Pelo contrário, a visão de que são gastos desnecessários pode ser vista em demasia sobretudo através de discursos como o de Darcy Ribeiro, pela exclusão no cômputo do FUNDEF ${ }^{6}$ do alunado da modalidade e/ ou a falsa disputa de verbas do FUNDEB $^{7}$ entre as etapas de ensino e EJA. Todavia, não é uma característica inata em ambos os casos. Houve um movimento social, isto é, um processo para que fosse construído essa imagem improdutiva e marginal da modalidade e dos sujeitos nela inseridos.

\section{O processo de construção do estigma como balança antagônica superior/inferior: os estabelecidos \& outsiders}

Elias \& Scotson (2000) se dirigem a uma região na Inglaterra para que pudessem entender os casos de violência existentes entre grupos sociais na comunidade de Winston Parva. Embora houvesse relações de interdependência e figuração ${ }^{8}$ existentes naquele espaço, Elias e Scotson investigaram quais eram os mecanismos utilizados para estigmatizar um determinado grupo, e dentro dessa relação de poder definir as hierarquias sociais dentro da comunidade, uma vez que haviam diferenças e semelhanças sobretudo entre as zonas 2 e 3 na cidade.

A única diferença mais expressiva entre as zonas 2 e 3 era o tempo que estavam naquela cidade. Em outros termos, a distinção entre as duas zonas estava marcada pela presença há mais tempo na região dos habitantes da zona 2, corroborando para que se sentissem superiores aos habitantes da zona 3, significando um elemento diferenciador nessa interação. No entanto, é importante frisar que os moradores da zona 2, chamados de "estabelecidos", rejeitavam completamente os moradores da zona 3 - conhecido como loteamento-, os "outsiders".

\footnotetext{
${ }^{6}$ Fundo de Manutenção e Desenvolvimento do Ensino Fundamental e de Valorização do Magistério. Programa anterior tendo sua vigência de 1996 até 2006 dando lugar ao Fundo de Manutenção e Desenvolvimento da Educação Básica e de Valorização dos Profissionais da Educação. O FUNDEB em 2020 se tornou política permanente no país criando uma grande expectativa quanto as possíveis alterações nos percentuais para cada etapa e modalidade ensino

${ }^{7} \mathrm{O}$ artigo "O financiamento da EJA no Brasil: repercussões iniciais do FUNDEB" de Marcelo Pagliosa Carvalho aponta diversas questões relacionadas ao financiamento da modalidade. A EJA possui o menor valor de repassar no cômputo/alunado.

${ }^{8}$ Conceitos que serão abordados no tópico seguinte
} 


\section{Intratextes-}

Estratégias como evitar contato com as pessoas do loteamento, estereótipos, generalizações, rotulações, entre outros, eram formas de diferenciar os moradores da zona 3 daqueles que estavam nas zonas 1 e 2 . Assim, os autores frisam que

O fato de alguns dos "sujeitos mais grosseiros" continuarem a morar no loteamento parecia confirmar reiteradamente essa imagem formada por eles. E o fato de a maioria dos residentes do loteamento já não pertencer a esse "tipo rude" de proletários, mas ser predominantemente composta de gente tão digna e bem-comportada quando os próprios "aldeões", não conseguia superar o sólido estereótipo que estes haviam formado a respeito deles e que era transmitido de geração a geração. (ELIAS \& SCOTSON, 2000, p. 112)

Ademais, os estigmas que os moradores da aldeia produziam sobre aqueles inseridos no loteamento, eram reproduzidos também pelos moradores da zona 3. Em suma, "a maioria deles parecia aceitar, ainda que a contragosto, o status inferior que lhes era atribuído pelos grupos já estabelecidos." (ibid, p. 113).

$\mathrm{Na}$ EJA não é diferente. Muitas pessoas atribuem o período longe da escola exclusivamente a si mesmas; se inferiorizam como sendo incapazes de aprender; e não entendem a modalidade como direito reconhecido. Tais pensamentos acarretam na pouca reflexão sobre o papel do Estado como agente promotor das desigualdades sociais. A ideia individualizada ainda é marcadamente forte nos discursos sobre êxito ou fracasso.

Retomando a obra dos autores, as famílias ruins que existiam na zona 3 eram minorias. Os próprios moradores do loteamento tinham a percepção desta realidade. Contudo, para os habitantes da zona 2, o comportamento negativo era generalizado. Como se todos naquele local fossem pessoas com comportamentos questionáveis

Os moradores da Zona 3, até certo ponto, tinham consciência de que a má reputação de seu bairro e seus aspectos mais desagradáveis deviam-se essencialmente, a uma minoria, a um grupo particular de famílias. Os moradores da Zona 2, por sua vez, falavam quase invariavelmente da "vida familiar ruim" e da "má conduta" da totalidade da Zona 3. Não percebiam a distinção entre a maioria de pessoas comuns, cujo estilo de vida e cuja conduta não diferiam acentuadamente dos deles, e a minoria de famílias desestruturadas, cuja conduta desviante atraía toda a sua atenção. (ibid, p. 120).

Além disso, como elemento fundamental para a construção de rotulações à zona 3, a fofoca, que os autores chamam de gossip, teve grande relevância nesta ação. Assim, eles destacam que a fofoca não é um fenômeno independente, não é algo isolado. Carece de uma 


\section{Intratextos-}

narrativa. E salientam que "O uso comum nos inclina a tomar por "fofocas", em especial, as informações mais ou menos depreciativas sobre terceiros, transmitidas por duas ou mais pessoas umas às outras.” (ibid, 2000, p.121). Em outras palavras, naquele contexto observado pelos autores, a fofoca tinha como finalidade inferiorizar os habitantes da zona 3.

Segundo os autores, a fofoca possui em sua estrutura dois tipos sendo a fofoca depreciativa [blame gossip] e a elogiosa [pride gossip], sendo

as fofocas depreciativas, referentes sobretudo a pessoas de fora, e as fofocas elogiosas, que traziam fama para o próprio indivíduo e seu grupo, o fluxo das fofocas continha simples itens de uso do grupo interno, notícias sobre amigos e conhecidos que eram interessantes em si mesmas. (ibid, p. 122)

No que diz respeito às estigmatizações, vale ressaltar que naquele contexto Elias e Scotson identificaram que a gossip possuía duas características. Ao mesmo tempo que a blame gossip era utilizada para inferiorizar os moradores do loteamento, a pride gossip correspondia a exaltação dos aldeões.

Vale ressaltar que historicamente a EJA possui uma relação de depreciação perante a sociedade. Isso significa dizer que a modalidade convive com aquilo que o autor denominou de blame gossip. Os adjetivos como "endêmicos", "inúteis", "ignorantes", para com os discentes eram utilizados com a finalidade de destacar a sua inferioridade pelo fato de não terem se escolarizado na infância ou juventude. Ao mesmo tempo que os diferencia com tais adjetivos, seja velado ou verbalizado a pride gossip está em ação para aqueles que estão escolarizados como superiores, sendo por exemplo, tidos como "alfabetizados", “úteis, "inteligentes", "normais".

Volvendo ao discurso de Darcy Ribeiro, embora a sua fala não esteja incorreta, uma vez que de fato este público já estava adaptado a sua condição de pessoas sem escolarização, pois, como Pinto frisa "o desenvolvimento fundamental do homem é de natureza social, faz-se pelo trabalho, e que o desenvolvimento não para pelo fato de o indivíduo permanecer analfabeto" (PINTO, 1983, p.62). Contudo, é uma declaração que carrega um tom preconceituoso deslegitimando este público ao que lhe estava assegurado. De outro modo, o direito à educação independente da idade, assim como nas entrelinhas soa como seres inferiores.

Perceba que há uma relação entre os moradores da zona 3 e os sujeitos da EJA no que se refere à similaridade que ambos possuem. Há uma falta de reconhecimento enquanto sujeitos pertencentes de determinado meio. No caso dos moradores, fica evidente que o marcador 


\section{Intratextos-}

diferencial entre as zonas 2 e 3 era exclusivamente o período em que chegaram aquela localidade. Em contrapartida, o demarcador dos sujeitos da EJA correspondia a ideia fortemente presente no século passado da necessidade de socorrê-los, pois, são pessoas que necessitam de uma instrução devido a sua condição. No entanto, tais características possuem uma fragilidade em seus discursos que é o preconceito. A tentativa de colocar aquele grupo social que é submetido a um estigma na condição de dominação ao mesmo tempo que há a ação de estimar socialmente aqueles que não estão neste grupo. Porém, não há absolutamente nenhuma manifestação que os diferenciam do ponto de vista intelectual e/ou socioeconômico dos locais onde figuram. Daí a necessidade de estigmatizá-los. Através dessa ação, conseguiriam manter a condição de dominação perante ao grupo marginalizado.

Além disso, é preciso observar as redes de interdependência expostas nas relações entre as zonas da região inglesa e a sociedade brasileira para com os sujeitos da EJA. Afinal, o trabalho é uma das figurações onde estão inseridos, inclusive relacionando-se mutuamente em determinadas contextos, seja os indivíduos das zonas localizadas na região de Winston Parva desempenhando funções semelhantes nas fábricas seja os sujeitos alfabetizados e os não alfabetizados ocupando funções afins no Brasil. Portanto, dentro desta relação nas duas situações a busca pelo poder e, consequentemente o ato de promover uma hierarquia ainda que inexistente na prática, eram componentes essenciais nessas relações.

A rigor, manter-se superior em relação ao outro grupo, estigmatizando-o de diferentes formas, é a utilização do discurso como elemento para se estabelecerem.

\section{Os conceitos de figuração e interdependência para a compreensão da EJA}

É primordial iniciar este tópico fazendo uma breve introdução de Norbert Elias. Em síntese, trata-se de um sociólogo alemão que desenvolveu suas pesquisas através do processo de longa duração, quer dizer, a análise através de um contexto mais duradouro para entender determinados costumes presentes no passado, como ainda impactam a sociedade atual. Nesse aspecto, é significativo pensar sobretudo os processos psicogenéticos e sociogenéticos ${ }^{9}$.

\footnotetext{
${ }^{9}$ Os termos psicogênese e sociogênese se referem a dois processos que ocorrem de modo recíproco no interior dos processos históricos de longa duração e vão se relacionar a mudanças no comportamento dos indivíduos que vão se amoldando e se modificando de acordo com a mudança dos fatos históricos e sociais, empreendidas no interior das sociedades. (BARBOSA, 2005)

Ver:

http://www.uel.br/grupo-estudo/processoscivilizadores/portugues/sitesanais/anais9/artigos/workshop/art21.pdf
} 


\section{Intratextos-}

Ademais, Elias utilizou do período que cursou medicina para com o auxílio das áreas que estudam o organismo, esmiuçar os fenômenos sociais e obter um maior entendimento do modus operandi da sociedade. Para ele, um bom sociólogo deve prezar sempre pelo entendimento do indivíduo enquanto ser biológico para compreender os aspectos sociológicos.

Outro elemento fundamental de Elias corresponde ao entendimento de que não existe indivíduo sem sociedade e nem sociedade sem indivíduo. Nesse sentido, ele tem uma compreensão distinta da ideia presente em diversos estudos de outros pesquisadores sobre a dicotomia entre indivíduo e sociedade. Para Elias,

[...] não se pode separar o indivíduo da sociedade, que eles constituem de fato dois níveis de observações distintas. Os fenômenos de grupos têm certas particularidades que se distinguem daqueles fenômenos individuais, mas sempre é preciso considerar os dois níveis simultaneamente. (ELIAS, 2001, p. 73)

No que se refere a definição de figuração, os autores discorrem sobre as diferentes posições que os indivíduos ocupam na sociedade. Essa ocupação por cada pessoa ou grupo social é um elemento importante para que a estigmatização seja eficaz a um grupo tido como outsider pelo estabelecido (ELIAS \& SCOTSON, 2000). Nesse sentido, a organização na qual os grupos ocupam posições sociais é a marca que podemos observar a respeito da definição. Ao pensarmos historicamente a EJA, ela sempre ocupou um lugar de marginalidade dentro da sociedade. A EJA é este grupo outsider (BECKER,2008) em diferentes aspectos. De modo geral, são jovens e adultos que não concluíram a educação básica no tempo tido como certo; são compostos por mulheres; pessoas pardas e negras; pessoas em regime semiaberto. Em diferentes papéis sociais a EJA apresenta grupos que estão à margem da sociedade, inferiorizados e vistos como desviantes do que é aceitável.

Elias (2006) frisa a despeito da figuração podendo ser entendida a partir da análise de que

[...] as sociedades humanas não são simplesmente um aglomerado cumulativo dessas pessoas. O convívio dos seres humanos em sociedades tem sempre, mesmo no caos, na desintegração, na maior desordem social, uma forma absolutamente determinada. É isso que o conceito de figuração exprime. Os seres humanos, em virtude de sua interdependência fundamental uns dos outros, agrupam-se sempre na forma de figurações específicas. Diferentemente das configurações dos outros seres vivos, essas figurações não são fixadas nem com relação ao gênero humano, nem biologicamente. (ELIAS, 2006, p. 28) 


\section{Intratextos-}

Para Brandão (2003), o conceito de figuração de Elias

refere-se à teia de relações de indivíduos interdependentes que se encontram ligados entre si a vários níveis e de diversas maneiras, sendo que as ações de um conjunto de "pessoas interdependentes interferem de maneira a formar uma estrutura entrelaçada de numerosas propriedades emergentes, tais como relações de força, eixos de tensão, sistemas de classes e de estratificação, desportos, guerras e crises econômicas". (BRANDÃO, 2003, p. 61 apud ELIAS \& DUNNING, 1992, p. 25-26)

Já o conceito de interdependência para Elias significa a relação de colaboração que cada indivíduo possui em relação às pessoas. Estamos sempre dependendo de algo em relação ao outro. Isso corresponde à ideia de que as relações não se pautavam exclusivamente a cooperação, mas também ao conflito. É importante frisar que os autores não trabalham com a ideia de interação social conforme outros autores da Sociologia, e sim com a rede de interdependência (ELIAS \& SCOTSON, 2000). Pois, conforme dito acima, indivíduo e sociedade são indissociáveis.

Elias (2011) relaciona os conceitos de figuração e interdependência de forma que

A rede de interdependência entre os seres humanos é o que os liga. Elas formam o nexo do que é aqui chamado configuração, ou seja, uma estrutura de pessoas mutuamente orientadas e dependentes. Uma vez que as pessoas são mais ou menos dependentes entre si, inicialmente por ação da natureza e mais tarde através da aprendizagem social, da educação, socialização e necessidades recíprocas socialmente geradas, elas existem, poderíamos nos arriscar a dizer, apenas como pluralidades, apenas como configurações. (ELIAS, 2011, p. 240)

Em suma, considerar os sujeitos que não se escolarizaram durante a infância e juventude como seres patológicos, desconsiderando os diferentes papéis que ocupam nas teias de relações de figuração e de interdependência, significa pautar que são indivíduos sem qualquer relação social. Tal concepção ao mesmo tempo que se caracteriza pela ingenuidade ao desconsiderar o processo de socialização desses sujeitos, tomando como base que a escolarização é o único caminho para se relacionarem com os outros, é também marcada pelo caráter preconceituoso diante de uma situação que está longe de ser endêmica.

Afinal, estar analfabeto não os impediu de dar inserção ao mercado de trabalho, de constituírem famílias e amigos, ocuparem igrejas e outros espaços de interação social. O 


\section{Intratextos-}

marcador da não escolarização pode ter dificultado em algum momento essa socialização. Mas não os impossibilitou como os estigmas a estes sujeitos pretendiam estabelecer classificandoos patologicamente.

A tensão que existe no ato de estar analfabeto é marcada pela relação de poder onde esta condição os coloca em condição de submissão. Através dessa condição é possível insinuar através do estigma que há uma inferioridade nos grupos marginais, mantendo assim a sua superioridade do grupo dominante.

\section{Estigma e outsiders: aproximações de Goffman e Becker a EJA}

O termo estigma para Goffman "...é usado em referência a um atributo profundamente depreciativo" (GOFFMAN, 2017, p.13). Dessa maneira, para uma melhor compreensão, o autor descreve três tipos de estigma,

Em primeiro lugar, há as abominações do corpo - as várias deformidades físicas. Em segundo, as culpas de caráter individual, percebidas como vontade fraca, paixões tirânicas ou não naturais, crenças falsas e rígidas, desonestidade, sendo essas inferidas a partir de relatos conhecidos de, por exemplo, distúrbio mental, prisão, vício, alcoolismo, homossexualismo, desemprego, tentativas de suicídio e comportamento político radical. Finalmente, há os estigmas tribais de raça, nação e religião, que podem ser transmitidos através de linhagem e contaminar por igual todos os membros de uma família. (GOFFMAN, 2017, p.14)

Há uma ideia estabelecida na sociedade de ordem meritocrática na qual o sucesso ou fracasso é atribuído ao indivíduo. Assim, desconsidera fatores exógenos ao indivíduo, fatores sociais que interferem no êxito ou não. Tal concepção errônea é base para a justificativa de que esses homens e essas mulheres jovens e adultos(as) que ainda não concluíram as etapas de ensino seja entendida como falta de esforço destes, convergindo com a sua perspectiva estigmatizadora definida por Goffman. À medida que se culpa o sujeito através da vontade fraca, crenças falsas ou distúrbio mental, por exemplo, o estigma está inserido. Afinal, reitero o caráter endêmico que estar analfabeto carregou por muito tempo.

Diferentemente dos estudos de Elias e Goffman, mas convergindo no aspecto social, Becker trabalha a questão do grupo social como dissemelhante ao padrão estabelecido, no qual os sujeitos da EJA encaixam-se devido a distinção dos jovens e adultos que não estão totalmente escolarizados. 


\section{Intratextes-}

Becker (2008) afirma que a condição de outsider advém de como o julgamento de outrem é utilizado para caracterizar aquele que supostamente infringiu uma regra ou convenção. Assim sendo, o autor destaca que

Todos os grupos sociais fazem regras e tentam, em certos momentos e em algumas circunstâncias, impô-las. Regras sociais definem situações e tipos de comportamentos a elas apropriados, especificando algumas ações como "certas" e proibindo outras como "erradas". Quando uma regra é imposta, a pessoa que presumivelmente a infringiu pode ser vista como um tipo especial, alguém de quem não se espera viver de acordo com as regras estipuladas pelo grupo Essa pessoa é encarada como outsider. Mas a pessoa assim rotulada pode ter uma opinião diferente sobre a questão. Pode não aceitar a regra pela qual está sendo julgada e pode não encarar aqueles que a julgam competentes ou legitimamente autorizados a fazê-lo. (BECKER, 2008, p.15)

Becker (ibid, p.15) destaca que pode haver questionamento das partes no que se refere comportamentos. Nesse sentido, as relações sociais e de pertencimento a um grupo são estabelecidas regras de convivência onde as semelhanças de comportamento, pensamento, gostos musicais, podem ser determinantes neste acolhimento.

A EJA caracteriza-se nesse aspecto. Afinal, os sujeitos que nela estão inseridos não conseguiram no "tempo certo" concluírem a educação básica. O fato de carregarem esse estigma e serem vistos como outsiders inicialmente os colocam como semelhantes. Logo, para além de torná-los um grupo coeso, há também a ideia de que são outsiders devido ao processo de não pertencimento à escola durante a infância e adolescência e ocupado outras figurações naquele momento.

Em consonância com as questões propostas por Elias, Goffman e Becker destacam o processo de construção das rotulações como algo gradativo. Há de ressaltar que o ponto em comum nos estudos que apresentamos de cada autor são importantes para entendermos a percepção social como também a construção da imagem do público que está inserido na EJA.

Assim sendo, é importante para entendermos o desenvolvimento utilizando os conceitos de estigma, figuração, interdependência e outsider. Desse modo, ao trazê-los ajuda-nos a entender que os sujeitos da EJA não nasceram com adjetivos descritos ao longo deste trabalho. Fora algo construído dentro da sociedade. A partir do momento que isso significou uma diferenciação entre grupos, o fato de não estarem alfabetizados em uma fase onde questões postas como chefiar o lar, prover o sustento da família estão como condicionantes do ser adulto, significou uma ruptura com o status quo. 


\section{Intratextos-}

Ainda que o país ao longo do século XX convivesse com altos índices de analfabetos, isso permitiu àquelas pessoas que estavam escolarizadas, sobretudo classes favorecidas, a olhar de cima para baixo aqueles sujeitos. Em outras palavras, promoveu conclusões como "nós somos normais" enquanto "eles não". Uma diferença que nada tem relação com o organismo do ser humano.

\section{Considerações finais}

Estudar a EJA através das ideias propostas por Elias impõe certa prudência e alguns desafios. Dito de outra maneira, em primeiro lugar Norbert Elias não dedicou seus trabalhos aos estudos da educação. Tampouco a modalidade de jovens e adultos assim como Becker e Goffman. Elias teve grandes influências em seus estudos tanto dos processos político e sociais na Alemanha com a ascensão do nazismo como também de costumes em seu país como na França, dando-lhe grande aparato textual ao que fora chamado de "O processo civilizador". Todavia, ainda que seus estudos não tivessem relação direta aos processos educacionais institucionais, seus trabalhos reconhecidos tardiamente, têm sido utilizados por diversos pesquisadores no país a fim de tentar compreender esse fenômeno social por abarcar pontos relevantes para investigarmos.

Dessa forma, este primeiro desafio de entender que as suas análises através do processo de longa duração em outros objetos, traz consigo a ideia da possibilidade que a sua genialidade proporcionou, na compreensão dos processos sociais para a construção desse estigma, do caráter marginal que os sujeitos da EJA adquiriram. Evidentemente, este trabalho não explorou profundamente através do seu processo de longa duração aspectos sobretudo oriundos dos séculos anteriores como a escravidão ou a Lei Saraiva, para a noção mais estreita dessa construção social que demarcou um status bastante inferiorizado àqueles que não possuíam a escolarização, muito embora o esforço para ajudar a compreender movimentos estigmatizadores na sociedade tenham sido inspirados pelo processo de longa duração de Elias.

O segundo desafio em suas teorias, já citado acima, é a análise precisa do processo de longa duração marcadamente presente em seus trabalhos. Nesse sentido, chamo a atenção para o trabalho que buscou refletir a EJA à luz das ideias eliasianas de forma reduzida em dois aspectos: 1) a provocação que o tema desperta muito embora carece de uma análise que se possa explorar os seus trabalhos em demasia e; 2) o caráter incipiente dos estudos sobre a modalidade, bem como a luz das ideias de Elias. Logo, conseguir interpretar a modalidade através das suas 


\section{Intratextos-}

ideias, considerando que o principal fator desta análise não fora explorado mais a fundo, foi o objetivo deste trabalho. Entretanto, a possibilidade de estender tal estudo é real.

O terceiro desafio é trazer autores que estão falando de aspectos relevantes para a compreensão da modalidade embora suas correntes de pensamento não estejam em simetria. Esse esforço reduzido nesse trabalho consiste em tentar apresentar as ideias de cada autor para que seja possível compreender questões ainda hoje presentes a respeito da modalidade e dos seus estudantes.

Ainda que os desafios postos sejam relevantes para este ensaio, é possível também através dos seus trabalhos perceber situações como a construção dos estigmas; a marginalização que um determinado grupo pode vir a receber; a busca por se colocar acima sobretudo ao pensarmos que as relações de poder não estão presentes apenas no controle do Estado como bem disse Foucault. São questões apresentadas brevemente que nos ajudam a perceber o caráter que se construiu aos sujeitos da EJA através de uma situação vista de forma depreciativa. O fato de muitas pessoas jovens e adultas estarem analfabetas significou uma ruptura na ordem natural possibilitando que estas pessoas fossem vistas de forma depreciada.

Em vista disso, à medida que estes sujeitos não sabiam ler ou escrever, eram postos como incapazes, seres endógenos e sem nenhuma utilidade a sociedade, desconsiderando que a sua inserção social é marcada pela teia de relações de interdependência e figurações sociais. Há uma teia marcada de dependência daqueles alfabetizados para com os analfabetos como também estes que não possuem a escolarização formal, possuem diversos outros papéis na sociedade que ao longo da vida evidenciam que a sua não participação dentro da escola e o contato com os saberes técnicos que a instituição proporciona, não restringiu a sua interação com outras pessoas e outras figurações. Como destaca Elias “As dependências recíprocas das pessoas não são obviamente sempre as mesmas em todas as sociedades nos seus vários estádios de desenvolvimento. (ELIAS, 2018, p. 147)

Portanto, buscar romper com determinadas concepções ainda presentes na sociedade é um processo que Elias chama atenção em seu livro "Norbert Elias por ele mesmo". É preciso buscar no passado a noção contextual e conjuntural para que se possa compreender o presente e lutar para alterar o futuro. Não devemos repetir os erros que ainda são vistos. Elias cada vez mais merece o seu devido reconhecimento, pois, suas ideias iluminam a sociedade para a real compreensão dos costumes e a necessidade de alterar comportamentos nocivos como a associação patológica aos sujeitos analfabetos. 


\section{Intratextos-}

Sem a análise de longa duração tomando um período mais profundo sobretudo da escravidão no Brasil; o objetivo dos políticos em promover a educação no nas quatro primeiras décadas e a participação ainda hoje do Estado $^{10}$ na atuação para certos estigmas estarem presentes, não é possível compreender de fato que a lógica da sobrevivência destes analfabetos não percorreu o processo natural presente pós Constituição de 1988. A sua inserção na escola ocorreu posterior às distintas figurações que obteve ao longo da sua trajetória. Sem tais elementos, o perigo de naturalizar certos comportamentos está sempre em nosso radar.

\section{REFERÊNCIAS}

BARBOSA, Sergio Servulo Ribeiro. A psicogênese e a sociogênese nas obras de Norbert Elias e a sua relação com a educação no processo civilizatório. In:IX Simpósio Internacional Processo Civilizador, 9., 2005, Ponta Grossa. Anais, Paraná: UEL, 2005

BECKER, Howard Saul. Outsiders: estudos de sociologia do desvio. Rio de Janeiro: Ed. Jorge Zahar, 2008

BRANDÃO, Carlos da Fonseca. Norbert Elias: formação, educação e emoções no processo de civilização. Ed. Vozes, 2003.

ELIAS, Norbert. Introdução à sociologia. Lisboa: Edições 70, 1980

O processo civilizador: uma história dos costumes (vol. 1). $2^{\text {a }}$ ed. Rio de Janeiro: Ed. Jorge Zahar editor, 2011

A sociedade dos indivíduos, Rio de Janeiro: Ed. Jorge Zahar, 1994

Os alemães. A luta pelo poder e a evolução do habitus nos séculos XIX e XX. Organização de M. Schroeter. Tradução de A. Cabral. Revisão técnica de A. Daher. Rio de Janeiro: Ed. Jorge Zahar, 1997

Norbert Elias por ele mesmo. Rio de Janeiro, Ed. Jorge Zahar, 2001

Introdução à Sociologia. Lisboa: Ed. 70, 2018

ELIAS, Norbert; DUNNING, Eric. A Busca da Excitação. Lisboa: Difel, 1992

\footnotetext{
${ }^{10}$ Recentemente o Governo lançou uma consulta pública datado 23/11/2020 no qual aborda questões sobre o Alinhamento da Educação de Jovens e Adultos (EJA) às diretrizes apresentadas na Base Nacional Comum Curricular (BNCC), e outras legislações relativas à modalidade. O texto apresenta uma série de controvérsias inclusive relacionando a modalidade à educação especial.

Disponível em

http://portal.mec.gov.br/index.php?option=com_docman\&view=download\&alias=166421 -texto-referencia-dcns-eja-1\&category_slug=novembro-2020-pdf\&Itemid=30192
} 


\section{Intratextes-}

ELIAS, Norbert.; SCOTSON, John. L. Os Estabelecidos e os Outsiders: sociologia das relações de poder a partir de uma pequena comunidade. Rio de Janeiro; Ed. Zahar, 2000

GOFFMAN, Erving. Estigma. Notas sobre a Manipulação da Identidade Deteriorada. $4^{\text {a }}$ ed. Rio de Janeiro. LTC. 2017

HADDAD, Sergio. A educação de pessoas jovens e adultas e a nova LDB. São Paulo, abr. 1997. Revista Brasileira de Educação, São Paulo, n. 14, p. 108-130, mai./ago. 2000.

PINTO, Álvaro Vieira. Sete lições sobre educação de adultos. São Paulo: Autores Associados: Cortez, 1983.

Recebido em: Junho de 2021 Aprovado em: Setembro de 2021. 